\title{
American Association of Colleges of Nursing
}

\section{Fact Sheet: Nursing Shortage}

The U.S. is projected to experience a shortage of Registered Nurses (RNs) that is expected to intensify as Baby Boomers age and the need for health care grows. Compounding the problem is the fact that nursing schools across the country are struggling to expand capacity to meet the rising demand for care given the national move toward healthcare reform. The American Association of Colleges of Nursing (AACN) is working with schools, policy makers, nursing organizations, and the media to bring attention to this healthcare concern. $A A C N$ is leveraging its resources to shape legislation, identify strategies, and form collaborations to address the shortage. To keep stakeholders abreast of the issues, this fact sheet has been developed along with a companion Web resource: www.aacnnursing.org/news-information/nursing-shortage.

\section{Current and Projected Shortage Indicators}

- According to the Bureau of Labor Statistics' Employment Projections 2014-2024, Registered Nursing (RN) is listed among the top occupations in terms of job growth through 2024. The RN workforce is expected to grow from 2.7 million in 2014 to 3.2 million in 2024 , an increase of 439,300 or $16 \%$. The Bureau also projects the need for 649,100 replacement nurses in the workforce bringing the total number of job openings for nurses due to growth and replacements to 1.09 million by 2024.

https://www.bls.gov/opub/m/r/2015/article/occupational-employmentprojections-to-2024.htm

- According to the "United States Registered Nurse Workforce Report Card and Shortage Forecast" published in the January 2012 issue of the American Journal of Medical Quality, a shortage of registered nurses is projected to spread across the country between 2009 and 2030. In this state-by-state analysis, the authors forecast the RN shortage to be most intense in the South and the West. http://ajm.sagepub.com

- In October 2010, the Institute of Medicine released its landmark report on The Future of Nursing, initiated by the Robert Wood Johnson Foundation, which called for increasing the number of baccalaureate-prepared nurses in the workforce to $80 \%$ and doubling the population of nurses with doctoral degrees. The current nursing workforce falls far short of these recommendations with only $55 \%$ of registered nurses prepared at the baccalaureate or graduate degree level. http://thefutureofnursing.org 
- In July 2010, the Tri-Council for Nursing released a joint statement on Recent Registered Nurse Supply and Demand Projections, which cautioned stakeholders about declaring an end to the nursing shortage. The downturn in the economy has lead to an easing of the shortage in many parts of the country, a recent development most analysts believe to be temporary. In the joint statement, the Tri-Council raises serious concerns about slowing the production of RNs given the projected demand for nursing services, particularly in light of healthcare reform.

http://tricouncilfornursing.org/documents/JointStatementRecentRNSupplyDemandPro jections.pdf

Contributing Factors Impacting the Nursing Shortage

\section{Nursing school enrollment is not growing fast enough to meet the projected demand for RN and APRN services.}

Though AACN reported a 3.6\% enrollment increase in entry-level baccalaureate programs in nursing in 2016, this increase is not sufficient to meet the projected demand for nursing services, including the need for more nurse faculty, researchers, and primary care providers.

www.aacnnursing.org/research-data

A shortage of nursing school faculty is restricting nursing program enrollments.

- According to AACN's report on 2016-2017 Enrollment and Graduations in Baccalaureate and Graduate Programs in Nursing, U.S. nursing schools turned away 64,067 qualified applicants from baccalaureate and graduate nursing programs in 2016 due to insufficient number of faculty, clinical sites, classroom space, and clinical preceptors, as well as budget constraints. Almost two-thirds of the nursing schools responding to the survey pointed to a shortage of faculty and/or clinical preceptors as a reason for not accepting all qualified applicants into their programs. www.aacnnursing.org/research-data

A significant segment of the nursing workforce is nearing retirement age.

- According to a 2013 survey conducted by the National Council of State Boards of Nursing and The Forum of State Nursing Workforce Centers, 55\% of the RN workforce is age 50 or older. http://jnr.metapress.com/content/m61518mn5001m025

- The Health Resources and Services Administration projects that more than 1 million registered nurses will reach retirement age within the next 10 to 15 years. http://bhpr.hrsa.gov/healthworkforce/reports/nursingworkforce/index.htm/

- According to data from the 2008 National Sample Survey of Registered Nurses released in September 2010 by the federal Division of Nursing, the average age of the RN population is 47.0 years of age, up slightly from 46.8 in 2004.

http://bhpr.hrsa.gov/healthworkforce/rnsurvey 
Changing demographics signal a need for more nurses to care for our aging population.

- Issued in May 2014, the U.S. Census Bureau report on An Aging Nation: The Older Population in the United States found that by 2050, the number of US residents age 65 and over is projected to be 83.7 million, almost double its estimated population of 43.1 million in 2012. With larger numbers of older adults, there will be an increased need for geriatric care, including care for individuals with chronic diseases and comorbidities. www.census.gov/population/projections/data/national/2012 .htm/

Insufficient staffing is raising the stress level of nurses, impacting job satisfaction, and driving many nurses to leave the profession.

- In the December 2016 issue of BMJ Quality \& Safety, the international journal of healthcare improvement, Dr. Linda Aiken and her colleagues released findings from a study of acute care hospitals in Belgium, England, Finland, Ireland, Spain, and Switzerland, which found that a greater proportion of professional nurses at the bedside is associated with better outcomes for patients and nurses. Reducing nursing skill mix by adding assistive personnel without professional nurse qualifications may contribute to preventable deaths, erode care quality, and contribute to nurse shortages. http://qualitysafety.bmj.com/content/early/2016/11/03/bmjqs- 2016005567.full?sid=03f7af68-8e6f-464c-b831-1f5571e26d66

- In the March 2005 issue of Nursing Economic\$, Dr. Peter Buerhaus and colleagues found that more than $75 \%$ of RNs believe the nursing shortage presents a major problem for the quality of their work life, the quality of patient care, and the amount of time nurses can spend with patients. Looking forward, almost all surveyed nurses see the shortage in the future as a catalyst for increasing stress on nurses (98\%), lowering patient care quality (93\%) and causing nurses to leave the profession (93\%).

High nurse retirement and turnover rates are affecting access to health care.

- In the September 21, 2015 issue of Science Daily, healthcare economist David Auerbach released findings from a new study, which found that almost $40 \%$ of registered nurses are over the age of 50. "The number of nurses leaving the workforce each year has been growing steadily from around 40,000 in 2010 to nearly 80,000 by 2020 . Meanwhile, the dramatic growth in nursing school enrollment over the last 15 years has begun to level off." www.sciencedaily.com/releases/2015/09/150921153457.htm

- In September 2007, Dr. Christine T. Kovner and colleagues found that $13 \%$ of newly licensed RNs had changed principal jobs after one year, and $37 \%$ reported that they felt ready to change jobs. These findings were reported in the American Journal of Nursing in an article titled "Newly Licensed RNs' Characteristics, Work Attitudes, and Intentions to Work." 


\section{Impact of Nurse Staffing on Patient Care}

\section{Many scientific studies point to the connection between adequate levels of registered nurse staffing and safe patient care.}

- In a study published in the journal BMJ Quality \& Safety in May 2013, researcher Heather L. Tubbs-Cooley and colleagues observed that higher patient loads were associated with higher hospital readmission rates. The study found that when more than four patients were assigned to an $\mathrm{RN}$ in pediatric hospitals, the likelihood of hospital readmissions increased significantly.

- In the August 2012 issue of the American Journal of Infection Control, Dr. Jeannie Cimiotti and colleagues identified a significant association between high patient-to-nurse ratios and nurse burnout with increased urinary tract and surgical site infections. In this study of Pennsylvania hospitals, the researchers found that increasing a nurse's patient load by just one patient was associated with higher rates of infection. The authors conclude that reducing nurse burnout can improve both the well-being of nurses and the quality of patient care.

- In a study publishing in the April 2011 issue of Medical Care, Dr. Mary Blegen and her colleagues from the University of California, San Francisco found that higher nurse staffing levels were associated with fewer deaths, lower failure-to-rescue incidents, lower rates of infection, and shorter hospital stays.

- In March 2011, Dr. Jack Needleman and colleagues published findings in the New England Journal of Medicine, which indicate that insufficient nurse staffing was related to higher patient mortality rates. These researchers analyzed the records of nearly 198,000 admitted patients and 177,000 eight-hour nursing shifts across 43 patient-care units at large academic health centers. The data show that the mortality risk for patients was about $6 \%$ higher on units that were understaffed as compared with fully staffed units. In the study titled "Nurse Staffing and Inpatient Hospital Mortality," the researchers also found that when a nurse's workload increases because of high patient turnover, mortality risk also increases.

- In a study published in the April 2010 issue of Health Services Research, Dr. Linda Aiken and colleagues found that lower patient-nurse ratios on medical and surgical units were associated with significantly lower patient mortality rates. The study is titled "Implications of the California Nurse Staffing Mandate on Other States."

- In the June 2009 issue of the International Journal of Nursing Studies, a research team lead by Dr. Koen Van den Heede found a significant association between the number of baccalaureate-prepared RNs on cardiac care units and in-hospital mortality. Data 
analyzed by this international team of researcher that included representatives from Belgium, Canada, the Netherlands, and the United States showed that there were 4.9 fewer deaths per 1,000 patients on intensive care units staffed with a higher percentage of nurses with bachelor's degrees.

- A growing body of research clearly links baccalaureate-prepared nurses to lower mortality and failure-to-rescue rates. The latest studies published in the journals Health Services Researchin August 2008 and the Journalof Nursing Administration in May 2008 confirm the findings of several previous studies which link education level and patient outcomes. Efforts to address the nursing shortage must focus on preparing more baccalaureate-prepared nurses in order to ensure access to high quality, safe patient care.

- In March 2007, a comprehensive report initiated by the Agency for Healthcare Research and Quality was released on Nursing Staffing and Quality of Patient Care. Through this meta-analysis, the authors found that the shortage of registered nurses, in combination with an increased workload, poses a potential threat to quality. Increases in registered nurse staffing was associated with reductions in hospital-related mortality and failure to rescue as well as reduced length of stays. In settings with inadequate staffing, patient safety was compromised.

- A shortage of nurses prepared at the baccalaureate level is affecting health care quality and patient outcomes. In a study published September 24, 2003 in the Journal of the American Medical Association (JAMA), Dr. Linda Aiken and her colleagues at the University of Pennsylvania identified a clear link between higher levels of nursing education and better patient outcomes. This extensive study found that surgical patients have a "substantial survival advantage" if treated in hospitals with higher proportions of nurses educated at the baccalaureate or higher degree level. In hospitals, a 10\% increase in the proportion of nurses holding BSN degrees decreased the risk of patient death and failure to rescue by $5 \%$.

\section{Impact of Nurse Staffing on Patient Care}

- Many statewide initiatives are underway to address both the shortage of RNs and nurse educators. For example, in January 2014, the University of Wisconsin (UW) announced the \$3.2 million Nurses for Wisconsin initiative - funded through a UW System Economic Development Incentive Grant - to provide fellowships and loan forgiveness for future nurse faculty who agree to teach in the state after graduation. This program was launched in response to projections that Wisconsin could see a shortage of 20,000 nurses by 2035. For a sampling of other state-based initiatives, visit www.aacnnursing.org/news-watch/partnerships. 
- Nursing schools are forming strategic partnerships and seeking private support to help expand student capacity. For example, the University of Minnesota announced a partnership with the Minnesota VA Health Care System in June 2013 to expand enrollment in the school's BSN program. With a focus on enhancing care to veterans, the VA committed $\$ 5.3$ million to the university to expand clinical placement sites, fund additional faculty, and support interprofessional engagement. For similar initiatives, visit www.aacnnursing.org/news-watch/partnerships.

- In September 2010, AACN announced the expansion of NursingCAS, the nation's centralized application service for RN programs, to include graduate nursing programs. One of the primary reasons for launching NursingCAS was to ensure that all vacant seats in schools of nursing are filled to better meet the need for RNs, APRNs, and nurse faculty. In 2016, more than 38,800 vacant seats were identified in baccalaureate and graduate nursing programs. NursingCAS provides a way to fill these seats and maximize the educational capacity of schools of nursing. www.nursingcas.org

- In July 2010, the Robert Wood Johnson Foundation (RWJF) released its Charting Nursing's Future newsletter focused on "Expanding America's Capacity to Educate Nurses." This policy brief describes the capacity innovations of 12 partnerships that are effectively addressing the nursing and nurse faculty shortages. Among the policy recommendations advanced in this brief are requiring all new nurses to complete a BSN program within 10 years of licensure and enhancing the pipeline into baccalaureate and graduate nursing programs. https://campaignforaction.org/resource/charting-nursingsfuture-expanding-americas-capacity-educate-nurses

- Since February 2002, Johnson \& Johnson has sustained the Campaign for Nursing's Future, a multimedia initiative to promote careers in nursing and polish the image of nursing. This multimillion dollar effort includes television commercials, a recruitment video, a Web site, brochures, and other visuals. www. discovernursing.com

Last Update: May 18, 2017 